This is the author's final, peer-reviewed manuscript as accepted for publication. The publisher-formatted version may be available through the publisher's web site or your institution's library.

\title{
Modeling of diafiltration processes for demineralization of acid whey: an empirical approach
}

A. Román, Gy. Vatai, A. Ittzés, Z. Kovács, P. Czermak

\section{How to cite this manuscript}

If you make reference to this version of the manuscript, use the following information:

Román, A., Vatai, Gy., Ittzés, A., Kovács, Z., \& Czermak, P. (2012). Modeling of diafiltration processes for demineralization of acid whey: An empirical approach. Retrieved from http://krex.ksu.edu

\section{Published Version Information}

Citation: Román, A., Vatai, Gy., Ittzés, A., Kovács, Z., \& Czermak, P. (2012). Modeling of diafiltration processes for demineralization of acid whey: An empirical approach. Journal of Food Process Engineering, 35(5), 708-714.

Copyright: @ 2011 Wiley Periodicals, Inc.

Digital Object Identifier (DOI): doi:10.1111/j.1745-4530.2010.00619.x

Publisher's Link: http://onlinelibrary.wiley.com/doi/10.1111/j.17454530.2010.00619.x/abstract

This item was retrieved from the K-State Research Exchange (K-REx), the institutional repository of Kansas State University. K-REx is available at http://krex.ksu.edu 


\title{
Modeling of diafiltration processes for demineralization of acid whey: an empirical approach
}

\author{
A.Román”, Gy.Vatai ${ }^{* a}$, A.Ittzés ${ }^{\mathrm{b}}$, Z.Kovács**,c ${ }^{*}$ P.Czermak ${ }^{\mathrm{c}}$ \\ ${ }^{a}$ Department of Food Engineering, Corvinus University of Budapest, Budapest, Hungary \\ ${ }^{b}$ Department of Mathematics and Informatics, Corvinus University of Budapest, \\ Budapest, Hungary \\ ${ }^{c}$ Institute of Biopharmaceutical Technology, University of Applied Sciences \\ Giessen-Friedberg, Giessesn, Germany
}

\begin{abstract}
In this paper, a mathematical model is provided to describe the dynamics of membrane diafiltration processes for desalting acid whey. A rich representation of the separation process is given due to the employment of concentration-dependent solute rejections in the design equations. We propose an experimental design and a suitable empirical method for parameter estimation. This technique supports the disciplined use of experimental data and reduces the number of necessary a-priori experiments. With the help of experimental data we demonstrate the power of the presented modeling method.
\end{abstract}

Key words: whey, demineralisation, nanofiltration, diafiltration, mathematical modelling

\section{Introduction}

Whey is a co-product of cheese-making and casein manufacture in the dairy industry. This dairy stream represents an excellent source of functional proteins and peptides, lipids, vitamins, minerals, and lactose. The annual volume of dairy whey produced globally exceeds 160 millions of tones

\footnotetext{
${ }^{*}$ Principal corresponding author

** Corresponding author

Email addresses: gyula.vatai@uni-corvinus.hu (Gy.Vatai), kovacs.zoltan@tg.fh-giessen.de (Z.Kovács)
} 
and it increases with an annual growth rate of $\approx 1-2 \%$ (Smithers, 2008). Historically, whey was discharged in the environment or sold for a low return as animal feed. With the introduction of modern processing technologies, such as electrodialysis, ion exchange, or membrane filtration, whey has quickly became a valuable raw material for the agri-food, biotechnology, medical, and related markets. Whey can be used as an ingredient in the formulation of diverse food products. Demineralization of whey is required for flavor improvement and to provide an inorganic salt content that is acceptable for the the intended use.

Nanofiltration (NF) provides a suitable degree of demineralization and it has reached industrial scale (Pouliot, 2008). NF membranes show diversity in separation behavior but they are common in rejecting highly charged ions in a higher degree, while in comparison, rejection of monovalent ions is much less. NF also rejects uncharged, dissolved material and positively charged ions according to the size and shape of the molecule in question. NF membranes retain the main organic components of whey, such as lactose and proteins in a high degree. The NF permeate of whey is water consisting of mainly monovalent salts and some other low molecular weight components in a lower extent.

A great number of experimental studies on whey NF is available in the open literature. As far as modeling aspects are concerned, whey represents a complex multi-component system. No comprehensive method has been provided so far to predict the dynamics of whey diafiltration. Several physical models have been employed to describe such processes. However, these quantitative methods in their presented form can find only limited applications. They are either restricted to describe the permeation of a single component, such as lactose (Cuartas-Uribe et al., 2007) or total organic carbon content (Minhalma et al., 2007), as a function of permeate flux that is adjusted by the transmembrane pressure; or they focused on evaluating the salt retention performance of an NF system operating in total recirculation mode (i. e. both permeate and retentate were returned to the feed vessel ensuring constant feed concentrations) (van der Horst et al., 1995).

In processes of practical interest, the concentrations of both salts and organics present in whey are subject to change, and a considerably interdependence in their permeation occurs. The aim of the present paper is to provide a simulation technique that accounts for such aspects. In Section 2.2 , we derive the governing differential equations for diafiltration. The presented mathematical framework gives a rich representation of diafiltration 
processes due to the employment of concentration-dependent solute rejections. We propose an experimental design (see Section 3.1) and a suitable empirical method (Section 3.3) to determine the model parameters. Finally, with the help of experimental data we demonstrate the power of the presented modeling method.

\section{Theory}

\subsection{Configuration of diafiltration}

The schematic representation of membrane diafiltration setting is shown in Fig. 1. In a batch operation, the retentate stream is recirculated to the feed

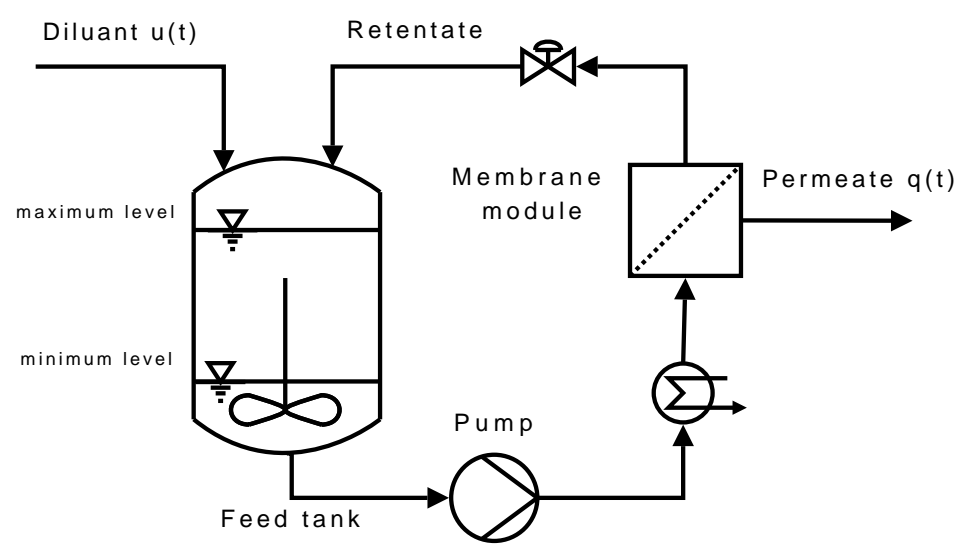

Figure 1: Schematic representation of diafiltration settings.

tank, and the permeate stream $q(t)$ is collected separately. During the operation, fresh solute-free diluant stream $u(t)$ (i.e. wash-water) can be added into the feed tank to replace solvent losses. We can distinguish between several configuration types: concentration mode (C), constant-volume dilution mode (CVD), and variable-volume dilution mode (VVD). They differ from each other in the water utilization strategy. Obviously, there is no diluant applied in concentration mode. In CVD, the flow rate of the wash-water is equal to the permeate flow rate. VVD is an operation mode in which fresh water is continuously added to the feed tank at a rate that is proportional but less than the permeate flow. This causes a simultaneous concentration of feed volume and removal of solutes with low membrane retentions.

In the next section, we provide a mathematical model in a compact form that unifies these batch diafiltration techniques. 


\subsection{General mathematical framework}

An essential stage in the development of the model is the formulation of appropriate mass balance equations. The proportionality factor $\alpha(t)$ is defined as the ratio of diluant flow $u(t)$ to permeate flow $q(t)$ :

$$
\alpha(t)=\frac{u(t)}{q(t)},
$$

where the diluant flow $u(t)$ is given as a product of the membrane area $A$ and the permeate flux $J(t)$. The change in the feed volume $V_{f}$ during the operation is given as

$$
\frac{d V_{f}}{d t}(t)=u(t)-q(t)
$$

Considering a multi-component system with $n$ solutes, and assuming that the diluant consists of no solutes, the mass balance for the solute concentrations yields

$$
\frac{d}{d t} V_{f}(t) c_{f, i}(t)=-q(t) c_{p, i}(t) \quad i=1,2, \ldots n,
$$

where $c_{p, i}(t)$ denotes the permeate concentration of solute $i$ at time $t$. Equation (3) can be rewritten in the following way:

$$
\frac{d V_{f}}{d t}(t) c_{f, i}(t)+V_{f}(t) \frac{d c_{f, i}}{d t}(t)=-q(t) c_{p, i}(t) \quad i=1,2, \ldots n
$$

Using Eq.(2) and recalling that $c_{p, i}(t)=c_{f, i}(t)\left(1-\mathcal{R}_{i}(t)\right)$, where $\mathcal{R}_{i}(t)$ is the rejection of solute $i$ at time $t$, we obtain, for $i=1,2, \ldots n$,

$$
V_{f}(t) \frac{d c_{f, i}}{d t}(t)=c_{f, i}(t)\left[q(t) \mathcal{R}_{i}(t)-u(t)\right]
$$

Thus, we have the following initial-value problems:

$$
\left\{\begin{array}{l}
\frac{d V_{f}}{d t}(t)=u(t)-q(t) \\
V_{f}(0)=V_{f}^{0}
\end{array}\right.
$$

and, for $i=1,2, \ldots n$,

$$
\left\{\begin{array}{l}
V_{f}(t) \frac{d c_{f, i}}{d t}(t)=c_{f, i}(t)\left[q(t) \mathcal{R}_{i}(t)-u(t)\right] \\
c_{f, i}(0)=c_{f, i}^{0}
\end{array}\right.
$$


which describe the evolution in time of the volume in the feed tank $V_{f}$ and of the feed concentration $c_{f, i}$. $V_{f}^{0}$ and $c_{f, i}^{0}$ denote respectively the initial feed volume and the initial feed concentration of the solute $i$. The estimation of the flow $q(t)$ and the rejection $\mathcal{R}_{i}(t)$ presented in Eqs. (4) and (5) can be carried out separately using the most convenient approach for the problem at hand. Possible strategies to determine the dependence of flux and rejection on the feed composition for a binary test solution are presented in our previous paper (Kovács et al., 2009). In this study, we introduce a specific method, as described in details in Section 3.3, to derive empirical relations for $q$ and $\mathcal{R}$.

\section{Materials and Methods}

The NF apparatus, the chemical properties of the applied whey and the sample analysis have been described in details in the previous work (Román et al., 2009). In brief, a commercial polymeric membrane, XN45 purchased from TriSep Co., was used for acid whey nanofiltration. All experiments were carried out at 20 bar transmembrane pressure, $40{ }^{\circ} \mathrm{C}$ temperature, and $3.0 \mathrm{~m}$ $\mathrm{s}^{-1}$ cross-flow velocity using a flat-sheet membrane with a filtration area of $0.046 \mathrm{~m}^{2}$. Total soluble solid, lactose, protein and fat content, as well as the ion composition ( $\mathrm{Na}, \mathrm{K}, \mathrm{Ca}, \mathrm{Mg}, \mathrm{P}$ ) of both permeate and feed samples were analyzed. Conductivity of feed and permeate streams were also monitored.

\subsection{Nanofiltration procedures}

Three NF experiments were performed as described in details hereafter.

1. Run no. 1 (experimental run for parameter fitting). The initial volume of the feed was $9.6 \mathrm{~L}$. A concentration mode operation was carried out by collecting $6.0 \mathrm{~L}$ permeate. Then, deionized water was poured into the feed tank in order to adjust the initial feed volume. The diluted solution was concentrated again to the same final volume. This procedure was repeated three times. During each concentration phase, four samples from the permeate pipe and four samples from the feed tank were taken always at the same time.

2. Run no. 2 (validation run). VVD mode with pure water as diluant was performed. The ratio of diluant inlet rate to permeate flow rate was kept at $\alpha=0.50$ in a quasi-continuous way: after every $1.0 \mathrm{~L}$ of collected permeate, $0.5 \mathrm{~L}$ pure water was added to the feed tank. 
During the operation, the volume in the feed tank was reduced from $9.6 \mathrm{~L}$ to $3.6 \mathrm{~L}$.

3. Run no. 3 (validation run). This test was carried out in VVD mode. The ratio of wash-water stream to permeate stream was set to 0.75 . Thus, both duration of process and water consumption were increased compared to run no. 2. The initial feed volume of $13.8 \mathrm{~L}$ was concentrated to $6.8 \mathrm{~L}$.

Note, that in this study we make partly use of the filtration data from our previous work (Román et al., 2009). The experimental data set of run no. 2 and no. 3 has been reported earlier, and it is used here for verification of the simulation method. Experimental run no. 1 was designed and performed exclusively for this modeling study. The filtration data of run no. 1 serve as input for the formulation of the mathematical model.

\subsection{Whey composition}

The NF feed liqueurs were supplied by a local dairy factory in Szeged, Hungary, and they originate from batch-production of cottage cheese. The crude whey solutions obtained from different batches were of similar composition, but they differed considerably in their fat content. The characteristics of the feed liquors are shown in Table.1.

Table 1: Compositions of crude acid whey used as feeds in the nanofiltration experiments

\begin{tabular}{lcccc}
\hline & & \multicolumn{3}{c}{ run } \\
component & unit & no. 1 & no. 2 & no. 3 \\
\hline fat & {$\left[\mathrm{g} \mathrm{L}^{-1}\right]$} & 1.5 & 3.7 & 6.3 \\
protein & {$\left[\mathrm{g} \mathrm{L}^{-1}\right]$} & 5.4 & 5.8 & 5.9 \\
lactose & {$\left[\mathrm{g} \mathrm{L}^{-1}\right]$} & 42.3 & 41.8 & 40.6 \\
dry weight & {$\left[\mathrm{g} \mathrm{L}^{-1}\right]$} & 60.0 & 63.3 & 64.0 \\
$\mathrm{~K}$ & {$\left[\mathrm{~g} \mathrm{~L}^{-1}\right]$} & 1476 & 1489 & 1513 \\
$\mathrm{Na}$ & {$\left[\mathrm{mg} \mathrm{L}^{-1}\right]$} & 406 & 372 & 404 \\
$\mathrm{Ca}$ & {$\left[\mathrm{mg} \mathrm{L}^{-1}\right]$} & 980 & 996 & 1004 \\
$\mathrm{Mg}$ & {$\left[\mathrm{mg} \mathrm{L}^{-1}\right]$} & 87 & 85 & 91 \\
$\mathrm{P}$ & {$\left[\mathrm{mg} \mathrm{L}^{-1}\right]$} & 627 & 722 & 640 \\
conductivity & {$\left[\mathrm{mS} \mathrm{cm}^{-1}\right]$} & 9.16 & 9.18 & 9.18 \\
\hline
\end{tabular}




\subsection{Response surface methodology}

Response surface methodology is an empirical modeling approach for understanding the quantitative relationship between multiple input variables and one output variable. It is a standard tool in statistical analysis and often adequate for process improvement in an industrial setting.

Considering one output, $y$, as a polynomial function of two inputs, $x_{1}$ and $x_{2}$. The function $\mathrm{y}=\mathrm{f}\left(x_{1}, x_{2}\right)$ describes a two-dimensional surface in the space $\left(x_{1}, x_{2}, \mathrm{y}\right)$. The equation of a quadratic response surface (QRS) is

$$
\begin{aligned}
y & =b_{0}+\ldots \\
& +b_{1} x_{1}+b_{2} x_{2}+\ldots \\
& +b_{4} x_{1} x_{2}+\ldots \\
& +b_{5} x_{1}^{2}+b_{6} x_{2}^{2}
\end{aligned}
$$

constant term

linear terms

interaction term

quadratic terms,

where $b_{0}, \ldots, b_{6}$ are suitable coefficients that are determined using the data obtained from the experimental run no. 1.

R-square statistic can be used to measure how successful the fit is in explaining the variation of the data. R-square is defined as the ratio of the sum of squares of the regression and the total sum of squares. A value closer to 1 indicates a better fit.

\section{Results}

Quadratic response surfaces were determined by fitting the model described in Section 3.3 to the experimental data of run no. 1. The lactose concentration and the feed conductivity were employed as two explanatory variables. Eleven response surfaces were computed by considering the permeate flux $q$ and the rejection of each component $\mathcal{R}_{i}$ as response variables. The goodness of the fits is shown in Table 2. The dynamics of a diafil-

\begin{tabular}{cccccccc} 
Table 2: The R-square statistics for flux and component rejections as response variables \\
\hline flux fat protein lactose dry weight $\mathrm{K}$ & $\mathrm{Na}$ & $\mathrm{Ca}$ & $\mathrm{Mg}$ & $\mathrm{P}$ & conductivity
\end{tabular} \begin{tabular}{lllllllllll}
0.9771 & 0.8701 & 0.9632 & 0.9193 & 0.9640 & 0.9411 & 0.9484 & 0.8656 & 0.8166 & 0.9657 & 0.9903 \\
\hline
\end{tabular}

tration process can be evaluated by simultaneously solving of Eqs. (4) and (5). The concentration of lactose and the conductivity in the feed tank is plotted versus operational time for the test and the validation runs in Fig.2. The time-profile of the concentrations in the feed tank is illustrated for each experimental run in Figs. 3-5. 

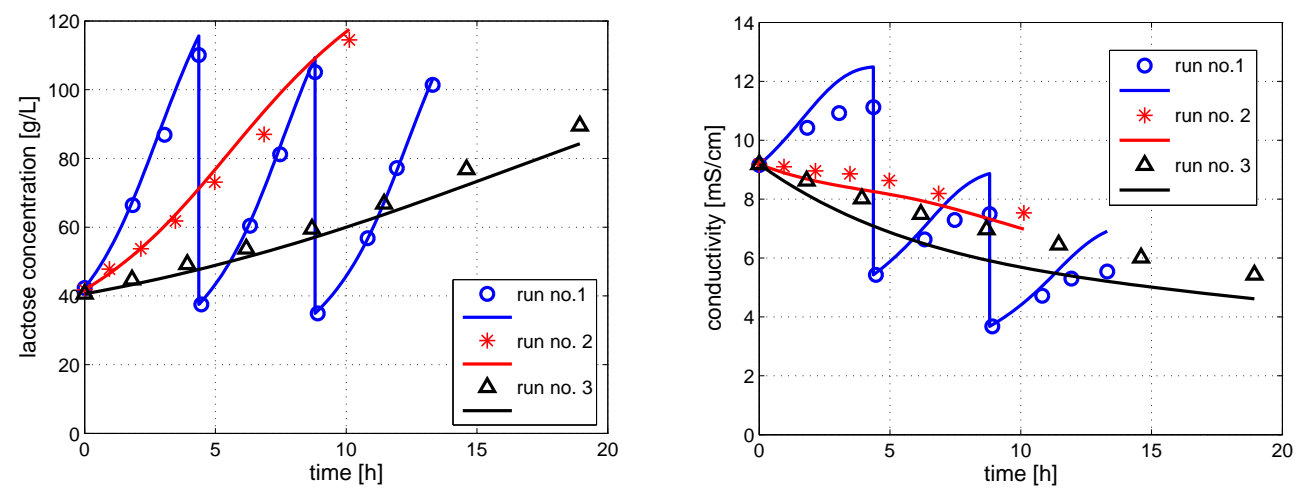

Figure 2: Concentration of lactose (left-side) and conductivity (right-side) in feed tank as functions of operational time for test and validation runs. Experimental data are illustrated with symbols and estimated values with continuous lines.
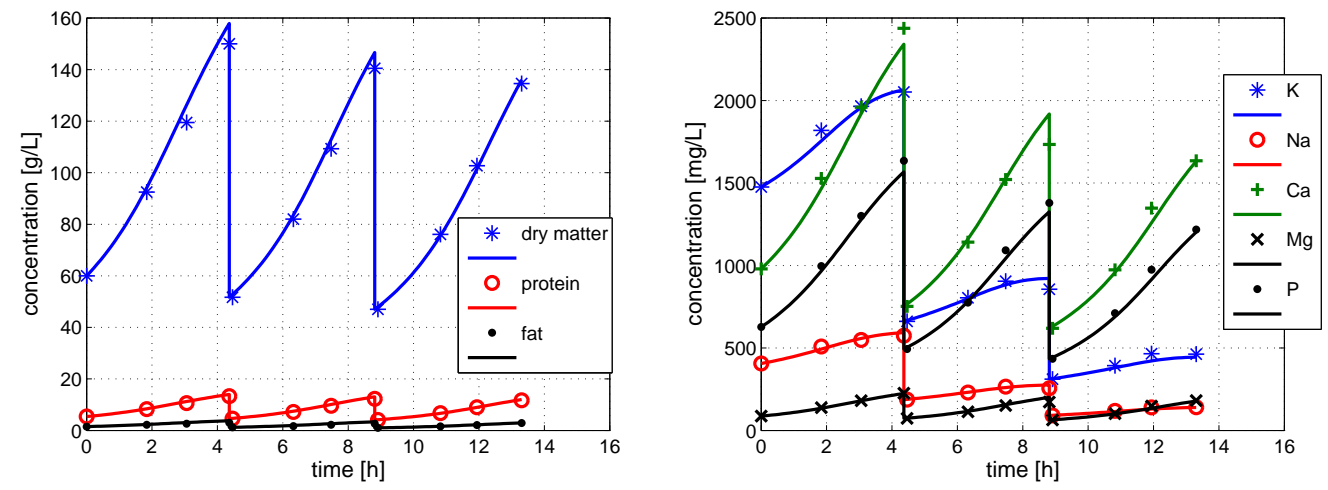

Figure 3: Feed concentrations of whey components as function of operational time for run no. 1. Experimental data are illustrated with symbols and estimated values with continuous lines.

\section{Discussion}

\subsection{Membrane response}

Due to the available chemical analytics, whey can be characterized with 10 physical quantities. As reported in Table. 1, the chemical characterization is not complete. There is no or limited information available on several components of whey, for instance citrate, chloride and other anions, amino acids, 

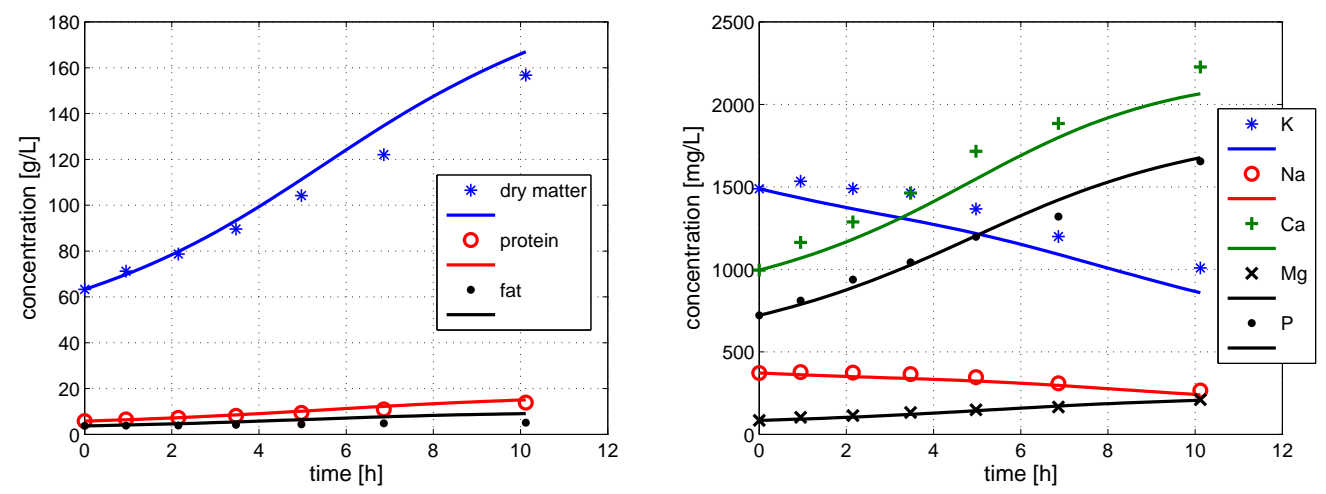

Figure 4: Feed concentrations of whey components as function of operational time for run no. 2. Experimental data are illustrated with symbols and estimated values with continuous lines.
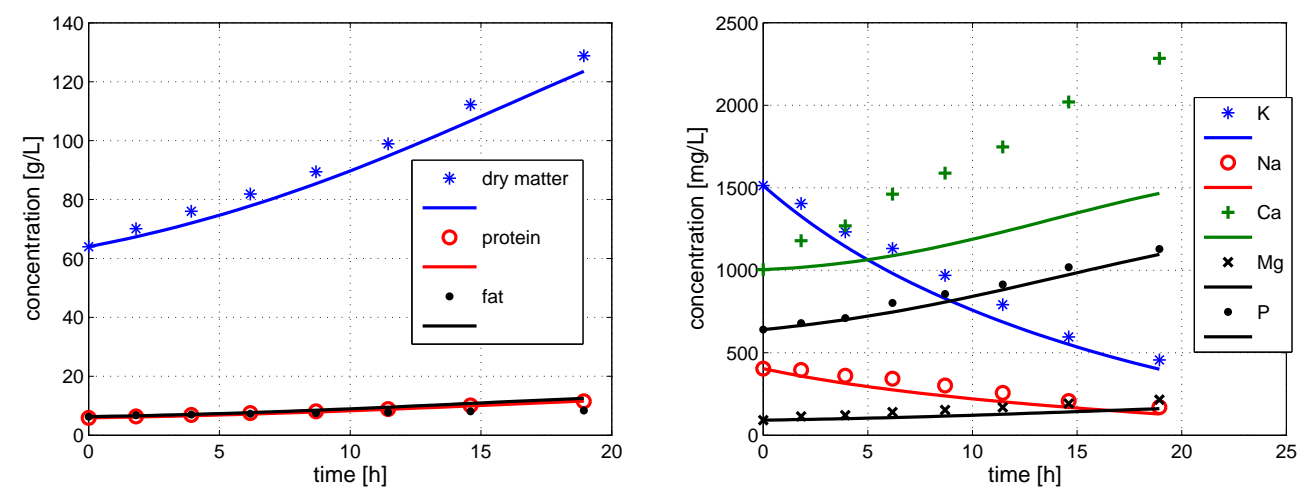

Figure 5: Feed concentrations of whey components as function of operational time for run no. 3. Experimental data are illustrated with symbols and estimated values with continuous lines.

peptides, or oligosaccharides. Moreover, many of the presented quantities are not solute-specific quantities, in fact, they represent certain collective features of a group of solutes of common types. In such a case, an empirical method might be a reasonable alternative over physical methods for process modeling.

The feed composition of whey determines the response of the membrane. 
The response is expressed in terms of permeate flow $q$ and rejection $\mathcal{R}_{i}$ for $i=1,2, \ldots 10$. The complex system consisting ten components was simplified by choosing lactose and conductivity as two explanatory variables. The selection is arbitrary and based on technological aspects. Lactose makes up a high proportion $(>75 \%)$ of the total whey solids. Due to its great contribution to the osmotic pressure of the solution, it can be indentified as a main factor affecting the membrane response. The conductivity measurement is an online, simple, and cheap method to gain information about the total salt content. Thus, it represents a quantity that is directly related to the separation objective.

The response surface model involving two explanatory variables appears to fit the data well as indicated in Table 2. It should be pointed out, that such a polynomial model might give poor estimates in predicting response outside of the experimentation region. Therefore, experimental run no. 1 has to be designed to provide data for the whole region of interest. The presented experimental design (run no. 1) covers a great area of interest, provides data points close to the region-boundaries, and gives evenly distributed data over the whole region. These features of the experimental design allow us to achieve a quantitative understanding of the system behavior over the region tested.

\subsection{Dynamic simulations}

The time varying behavior of the system was evaluated by combining the QRS model with Eqs. (4) and (5). Note that the system can be described by three state variables; these are the feed volume, the feed lactose concentration, and the feed conductivity. In general, good predictions were obtained. An exception is the estimation of the calcium ion concentration for run no. 3. Calcium ions might be involved in complex formation and tend to precipitate in certain circumstances (Butylina, 2007; Rice et al., 2009). These phenomenon might influence both membrane retention and chemical analysis. However, these facts do not explain why the observed rejection shows an unusual trend in run no. 3 only. A mass balance calculation with the experimental data is conducted for the initial liqueur and for the final product. The resulting mass of calcium is $13.9 \mathrm{~g}$ and $15.5 \mathrm{~g}$, respectively. This increase might indicate an error in the chemical analysis, rather than a failure of the presented simulation tool. In order to clarify this matter further laboratory experiments are needed. 
Apart from the calcium concentration in run no. 3, an overall good fit between predicted and measured data is achieved. This indicates that the provided method might be a useful simulation tool for whey diafiltration processes. We have presented a general mathematical model in a compact form. The dynamic behavior of all types of diafiltration configurations can be predicted without having to modify the given mathematical framework. This formal tool supports the disciplined use of experimental data, and reduces the number of necessary a-priori experiments. The presented simulation technique can support decision makers in finding the best wash-water utilizing profile for a given engineering design problem.

\section{Acknowledgment}

This research is a cooperative effort. The first author would like to acknowledge to the Hungarian Ministry of Education and Culture (OKM) for the "Deák Ferenc" Scholarship, and the Hungarian National Scientific Foundation OTKA (K 68596) for its sponsorship. The fourth author would like to thank the Hessen State Ministry of Higher Education, Research and the Arts for the financial support within the Hessen initiative for scientific and economic excellence (LOEWE-Program).

\section{List of Symbols}

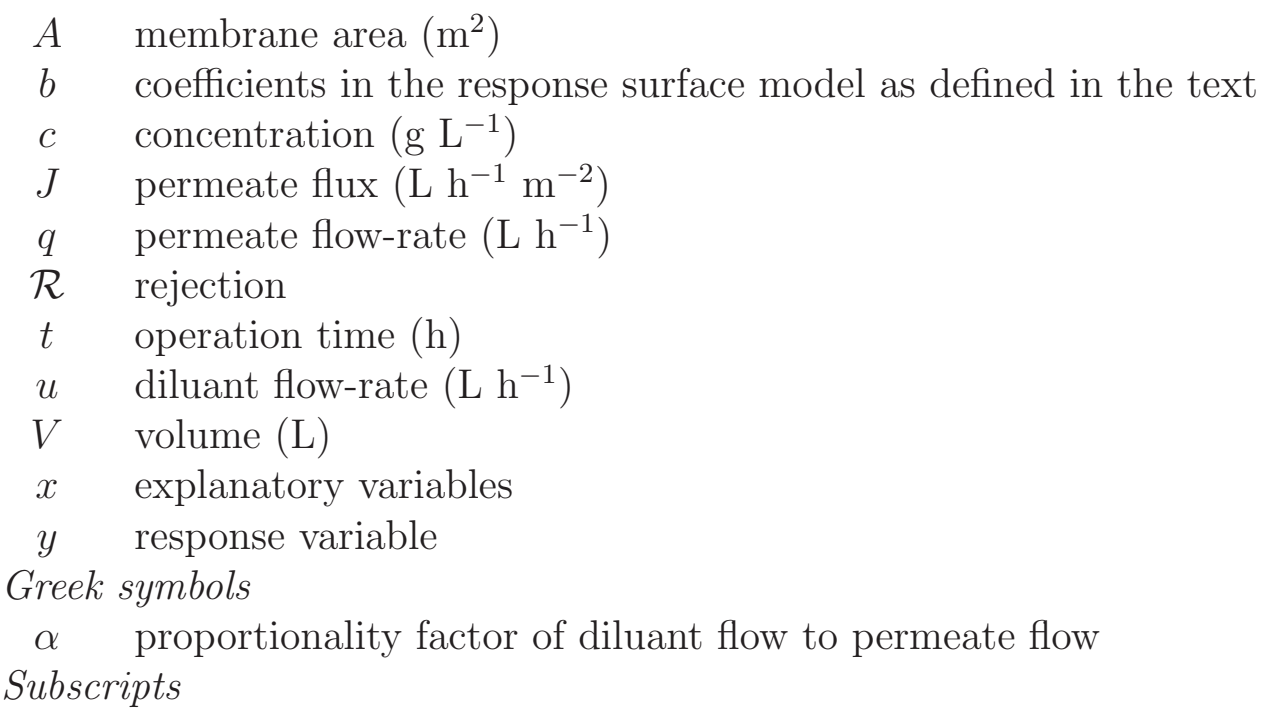




$\begin{array}{cl}d & \text { diluant } \\ f & \text { feed } \\ i & \text { component } \\ n & \text { number of components } \\ p & \text { permeate } \\ w & \text { wash-water } \\ \text { Abbreviations } \\ \mathrm{C} & \text { concentration mode } \\ \text { CVD } & \text { constant volume dilution mode } \\ \text { VVD } & \text { variable volume dilution mode } \\ \text { QRS } & \text { quadratic response surface }\end{array}$

\section{References}

G. W. Smithers, Whey and whey proteins - 'From gutter-to-gold', International Dairy Journal 18 (2008) 695-704.

Y. Pouliot, Membrane processes in diary technology - From a simple idea to worldwide panacea, International Dairy Journal 18 (2008) 735-740.

B. Cuartas-Uribe, M. Vincent-Vela, S. Álvarez-Blanco, M. Alcaina-Miranda, E. Soriano-Costa, Nanofiltration of sweet whey and prediction of lactose retention as a function of permeate flux using the Kedem-Spiegler and Donnan Steric Partioning models, Separation and Purification Technology 56 (1) (2007) $38-46$.

M. Minhalma, V. Magueijo, D. P. Queiroz, M. N. de Pinho, Optimization of Serpa cheese whey nanofiltration for effluent minimization and by-products recovery, Journal of Environmental Management 82 (2) (2007) 200 - 206.

H. C. van der Horst, J. M. K. Timmer, T. Robbertsen, J. Leenders, Use of nanofiltration for concentration and demineralization in the dairy industry: Model for mass transport, Journal of Membrane Science 104 (3) (1995) 205 -218 .

Z. Kovács, M. Discacciati, W. Samhaber, Modeling of batch and semi-batch membrane filtration processes, J. Membr. Sci. 327 (2009) 164-173.

A. Román, J. Wang, J. Csanádi, C. Hodúr, G. Vatai, Partial demineralization and concentration of acid whey by nanofiltration combined with diafiltration, Desalination 241 (1-3) (2009) 288 - 295. 
S. Butylina, Effect of Physico-chemical Conditions and Operating Parameters on Flux and Retention of Dfferent Components in Ultrafiltration and Nanofiltration Fractionation of Sweet Whey, Ph.D. thesis, Lappeenranta University of Technology, Lappeenranta, Finland, 2007.

G. Rice, A. Barber, A. O'Connor, G. Stevens, S. Kentish, Fouling of NF membranes by dairy ultrafiltration permeates, Journal of Membrane Science 330 (1-2) (2009) 117 - 126. 